\title{
The ethics of allocation of scarce health care resources: a view from the centre
}

\author{
K C Calman Chief Medical Officer, Department of Health, London
}

\section{Author's abstract}

Resource allocation is a central part of the decisionmaking process in any health care system. Resources have always been finite, thus the ethical issues raised are not new. The debate is now more open, and there is greater public awareness of the issues. It is increasingly recognised that it is the technology which determines resources. The ethical issues involved are often conflicting and relate to issues of individual rights and community benefits. One central feature of resource allocation is the basing of decisions on the outcomes of health care and on their subsequent economic evaluation. The knowledge base is therefore of great importance as is the audit of results of clinical treatment. Public involvement is seen as an integral part of this process. For all parts of the process, better methodologies are required.

\section{Introduction}

This topic is an important one and one of great interest to the Chief Medical Officer (CMO), who is a senior civil servant and acts as the medical adviser to the UK Government. However, as many of the decisions are of a political nature, it is important to set out at the start that the CMO is not a politician, and the appointment is not a political one. May I also say at the outset that the purpose of allocating resources is to help people and to act in the best interests of both the individual and the population. This presentation therefore is about people and how health and health care can be improved.

It might be useful to say a word about the post of CMO as this raises some important general issues about the allocation of resources. The CMO is the Chief Medical Adviser to the Government and has responsibilities which go across Government and do not apply only to the Department of Health. This immediately raises two questions. The first is the allocation of resources across Government to fund a wide range of issues, including health. The second is

\section{Key words}

Ethics; allocation of health care resources; education; outcomes. the use of the resources of one country to assist in the improvement of the health of others. These are necessary issues to raise before dealing with the more limited area of allocation of resources for health services. The funding of utilities such as transport, police, education, environment, etc, many of which will have a more important impact on health than spending on health care, is entirely relevant to improving the health of the nation. Indeed, when the determinants of health are reviewed health services are perhaps the least important in improving health. This is therefore the first part of resource allocation which requires a political decision.

In national terms part of the budget is used for overseas aid, some of which will be used to fund health-related projects in other parts of the world. Thus resources which might have been used to improve health and health care in one country are used in another. There is thus the immediate issue of dividing up the overall national cake, and assessing how much we can contribute to overseas health issues.

When these decisions have been made, the allocation to the Department of Health, whose responsibilities also go beyond the funding of the National Health Service and cover broader health and social issues, can then be identified.

Within this budget that part for health services can then be allocated, and it is this which is the subject of this presentation. Thus it is important to remember that before resources are allocated to health care or health services, other issues will have been considered, which in turn might be more important to improving the health of the population.

With that as an introduction this paper will now consider the allocation of resources to health care, and will raise the basic ethical issues involved, discuss the issue of outcomes and effectiveness in relation to making choices, add to this the importance of economic evaluation, and finally deal with the introduction of new technology.

In each of these it should be noted that it is the technology which determines both the particular ethical issue, and the resources required. As an example, the patient with a cancer which cannot be cured (but who still requires care), presents a different problem ethically and from a resource point of view, 
from a patient in whom the technology allows a high probability of cure. The introduction of an effective treatment for HIV infection would have a considerable impact on resources, and might even reduce costs. If an operation which means that a patient is in hospital for an average of seven days, was to be replaced by drug therapy instead (as has happened in ulcer surgery) then it can be clearly seen that the technology defines the resource. This also implies, and I will return to this, that one of the key methods in searching for methods to allocate resources, is to invest in research and development, as this is likely to be the major determinant of the resource.

The second point by way of introduction, is that resources have always been scarce, and the issues raised are therefore not new. In the past most of the decisions were made by doctors. Now the debate is more visible and politicians and the public are more aware of the issues. This is the second major theme of this paper, that of the need for public involvement in decision-making about the allocation of resources.

Finally, there is the very important question, which is a philosophical one, about the purpose of health. Why do we need to be healthy, and why do we need a certain level of health care? The response to this will be to set the value base, and this value will be another major determinant of the allocation of resources. Health can either be a means or an end. The answer selected will be part of the value base, and will be in the equation when resources are allocated. My own position is that health is a means towards fulfilling potential and improving quality of life. It is not an end in itself.

\section{Ethical issues in health care}

The role of ethics in health care is first to clarify thinking about the topic, secondly to assist in the analysis of the issues involved, and finally to provide the individual or the organisation with a way to support a particular course of action. The ethical framework will be familiar to this audience. It will be clear however, that these principles can be, and often are, conflicting. They include justice, beneficence, non-maleficence, utility and autonomy. The major conflict is between utility and autonomy, and the concept of justice; it relates to the distinction between the rights of the individual and the needs of the population. There are many current examples in this country, and beyond, where large sums of money have been spent on individual patients, a major consequence of which is to reduce the amount which can be spent on others. This raises in a most practical way the purpose of health, for the individual and the community, and the need to consider effective methods of resource allocation.

In general doctors, and other health care professionals, have a particular concern for individuals. However, the commitment of resources to one patient means that they cannot be used for others.
Resources in this context relate not only to financial factors, but also to skills, time and facilities. We may make a mistake if we think of resources in a narrow way and only in relation to money.

Daniel Callahan, in his book, What Kind of Life (1), proposes a most useful hierarchy of health and health care, which I have modified to make it more relevant to the United Kingdom. It provides a framework within which to consider ways in which resources might be allocated. First, he postulates a caring society, and the right of all individuals to be cared for. This does not imply that all individuals require treatment or that society should provide an institutional setting for their care. It does imply, however, that there is a responsibility for us all to care. This relates to the importance of the value base and is indeed central to any value base. Second, there should be a public health system which provides the basic essentials of water, air and shelter, and encourages prevention of ill health, immunisation, health promotion, and a clean environment. Next there should be a primary health care service, and an associated accident and emergency service. Within the UK the primary care service is first-class and much of the care, preventative services and health promotion is carried out in the community. This leads on to the establishment of clinical services of known value, and further to the need to have expensive or special services planned on a national basis. Both of these have a need to be outcome-based, and to be related to the effectiveness of the procedures. Finally, the framework requires that new procedures are properly evaluated. Indeed, before the introduction of research procedures into clinical practice the development phase requires careful follow-through.

The key to this scheme is the requirement to have outcome-information on clinical procedures. This is the first prerequisite for resource allocation.

\section{Outcome information}

Knowledge of the outcome and effectiveness of treatment is essential if we are to determine how $ᄋ$ resources should be allocated. This is the knowledge $N$ base. Measuring outcomes is not easy in many clinical situations. But in ethical and professional $O$ terms it is necessary that doctors and other professionals know what they are doing, why, and $\underset{\Phi}{ }$ what the results of the procedures are. One method $\stackrel{?}{?}$ which can be of help in this is the process of clinical 0 audit. This is the systematic evaluation of clinical procedures based on defined standards of quality. The development of guidelines of good clinical $\underset{\mathbb{D}}{\mathbb{D}}$ practice is also part of this process. In the UK we have set up a Clinical Outcomes Group, chaired jointly by the Chief Nursing officer and myself, $\delta$ to take this process forward, and it is strongly supported by research initiatives. It is an ineffective, and I would also submit, an unethical, use of $\rightleftharpoons$ resources, for a doctor, or any other health care 
professional, to use a treatment or procedure without taking steps to assess its outcome and value to patients. In particular, procedures which are ineffective or harmful should not be carried out. This is not to inhibit research or new ways of treatment. Indeed this should be encouraged, as research carries with it the obligation and the responsibility to evaluate. However, the conclusion is clear. The first step in the allocation of resources (defined in the broad way as previously described) should be based on the outcomes and effectiveness of treatment. This is a clear professional responsibility and is at the same time a major challenge.

If outcomes are central to the allocation of resources, should allocation therefore be based on measures of performance or audit? For example, in vascular surgery it is well known that those who perform procedures infrequently generally have poorer results than those who carry out many such operations. In future it is likely that those who commission or purchase care will take that information into account.

Outcomes and quality are clearly related. Quality is difficult to define. In Robert Pirsig's book, Zen and the Art of Motorcycle Maintenance (2), he describes it as elusive. In his more recent book, Lila (3), he relates it to values. I too feel that quality is about what we value and how we try to ensure that what we value is maintained and assured.

One further factor has recently been debated in this country, relating to how resources are both allocated and addressed. Lifestyle, notably in relation to cigarette smoking has been suggested as a factor which can be used in determining which patients should be treated, and what resources should be allocated to them. The argument put forward by those who have suggested this, is based on outcomes - patients who continue to smoke have a poorer outcome in some clinical situations. The Department of Health has watched with interest this debate in the press on a clinical matter. The General Medical Council has made it clear that all patients should be treated equally, regardless of lifestyle.

Professional education is a key part of outcome evaluation. The competence of individual professionals is of critical importance and must be reflected in continuing education. There is an ethical responsibility to keep up to date and to provide the patient with the most appropriate therapy.

Thus the role of health professionals is threefold: first to provide the best care to individual patients, second to consider the community in which they work, and finally to make the most effective use of resources. This latter I consider to be a key part of professional practice.

\section{Economic evaluation}

Once the effectiveness of treatment has been demonstrated, the next step is to carry out an economic evaluation. Thus, though a treatment may be effective it may not be cost-effective when compared to other methods. The obvious example of this relates to drug therapy where a number of drugs of equal effectiveness for the same condition may have quite different costs. Further, some treatments may be very expensive, though effective, and judgements have to be made about their affordability in relation to the overall allocation of resources - the individual versus the community. Economic evaluation and a value-for-money exercise are thus the second part of the process. The methodology for carrying out this economic evaluation requires further work. The use of QALYs - quality adjusted life years - is one way forward but other methods are urgently needed. In most instances a judgement is made about what is, or is not, affordable.

\section{Changing the technology}

The first two principles, effectiveness and economic evaluation, are the main ways by which allocations are made. But there is a third aspect of the process which must also be considered. This relates to changing and improving the technology, which will inevitably have resource consequences. A good example of this is the change in practice in the management of a myocardial infarction. The length of stay has been reduced from a few weeks to a few days. The motivation for this was not to save money - though that was a consequence - but was based on outcome studies and its purpose was to benefit patients. There must be many other procedures in current practice which would benefit from a radical review of the evidence. There is little point in seeking new resources when existing ones could be more effectively used and resources released. This is one of the great professional challenges.

New technology on the other hand can increase resource requirements when a new area of clinical work is opened up, and the history of medicine is the story of these discoveries: antiseptic surgery, antibiotics, immunisation, transplantation, cancer chemotherapy. However, investment in research and development is the only way to ensure that change and improvement in health and health care continues. This issue is not a new one to either patients, professionals or politicians. The question is how to identify new resources for such developments. In addition, demographic changes, particularly in the elderly population, are also likely to require new resources, once again emphasising the need for new ideas, research and innovative thinking. There are no easy answers to these issues. All require judgement, as uncertainty as to the best course remains. Indeed, resource allocation is an exercise in the management of uncertainty. 


\section{Public involvement}

At the beginning of this presentation the importance of people was emphasised, first because they are the focus of the exercise, and secondly because of the need to ensure that they are fully involved in the process. This may either be as a patient or as a member of the public. Emphasising people as the focus of the exercise is necessary because patients must be adequately informed and involved in decision-making. This is no more than good clinical practice, yet it is often neglected. In this scenario patients and their families are seen to be part of the resource allocation process, aware of the range of options, possible outcomes and success rates.

In measuring outcomes, patients' views are also central. There may well be differences between what a patient thinks is a good outcome and what the professional thinks. These differences need to be explored.

The second issue, how to ensure that the public is fully involved in the decision-making process, is more problematic because the methodology is not so clear. How do we adequately involve the public in resource allocation issues? If we believe that this is important then it is our responsibility to find ways. The experience in Oregon has shown some of the opportunities and problems (4). There is no lack of issues, the press and media are full of resource allocation issues with, one day, campaigns to ensure treatment of individual patients, often at great expense, and with unproven methods of treatment, and the next, stories about the lack of resources. These are issues of great public importance and I welcome the debates which occur around them. The public are highly sophisticated, I am one of them, and we neglect them at our peril.

In the words of Thomas Jefferson in 1820: 'I know of no safe depository of the ultimate powers of society but the people themselves; and if we think them not enlightened enough to exercise their control with a wholesome discretion, the remedy is not to take it from them, but to inform their discretion' (5).

\section{The role of the CMO}

In the discussion so far I have emphasised the importance of the professional contribution to resource allocation. But what does the $\mathrm{CMO}$ add to this? First, an overall and national view with an interpretation of the special pleading which comes from some groups and individuals. Second, the stimulation of outcome research so that clinical? practice is based on effective procedures, and the facilitation of the development of guidelines and good practice. Thirdly, his efforts to ensure that the education processes are able to pick up new⿳亠丷厂 developments, and an encouragement of audit, peerø review and teamwork. Fourthly, an insistence that continuing education forms an integral part of clinicals practice. And finally, he has a responsibility to assist $\vec{\circ}$ ministers in making judgements on resource $\vec{\overrightarrow{ }}$ allocation based on outcomes, an effective knowledge ${ }_{\sigma}$ base, economic factors and the taking into account of the ethical principles raised earlier in this paper.

\section{Conclusion}

The topic of resource allocation is fundamental too improving health, delivering health care and improv- ing quality of life for individuals and the community. That is its primary purpose. In this paper it is suggested that the two principles of outcome evalu- $\vec{c}$ ation and economic appraisal are central. However, ase it is the technology which determines resources; investment in research and development is crucial.o There is a clear need for better methodologies in outcome research, economic evaluation and publico involvement. If we believe things can be improved, and I do, then this is a major challenge to us all.

This paper is based on a presentation given to the Fifth International Conference on Medical Ethics at Imperial College, London.

Dr Kenneth C Calman, MD, PhD, FRCS (Glas Ed.), त्ञ FRCP (Lond Ed), FRCGP, FFPHM, FRSE, is Chief. Medical Officer at the Department of Health, London.

\section{References}

(1) Callahan D. What kind of life: the limits of medical progress. New York: Simon and Schuster, 1990.

(2) Pirsig R M. Zen and the art of motorcycle maintenance. तु London: Bodley Head, 1974.

(3) Pirsig R. Lila: an inquiry into morals. London: Bantami Press, 1991.

(4) The Oregon experiment. The Oregon Medicaid prioritysetting project. Portland: Medical Research Foundation of Oregon, 1989.

(5) Jefferson T. Letter to William Charles Jarvis 28th Sept黑 1820. 